\title{
The Effect of Microwave Radiation on Prickly Paddy Melon (Cucumis myriocarpus)
}

\author{
Graham Brodie, Carmel Ryan, and Carmel Lancaster \\ Melbourne School of Land and Environment, Dookie Campus, University of Melbourne, Nalinga Road, \\ Dookie, VIC 3647, Australia \\ Correspondence should be addressed to Graham Brodie, grahamb@unimelb.edu.au
}

Received 27 June 2011; Accepted 5 September 2011

Academic Editor: David Clay

Copyright ( $\odot 2012$ Graham Brodie et al. This is an open access article distributed under the Creative Commons Attribution License, which permits unrestricted use, distribution, and reproduction in any medium, provided the original work is properly cited.

The growing list of herbicide-resistant biotypes and environmental concerns about chemical use has prompted interest in alternative methods of managing weeds. This study explored the effect of microwave energy on paddy melon (Cucumis myriocarpus) plants, fruits, and seeds. Microwave treatment killed paddy melon plants and seeds. Stem rupture due to internal steam explosions often occurred after the first few seconds of microwave treatment when a small aperture antenna was used to apply the microwave energy. The half lethal microwave energy dose for plants was $145 \mathrm{~J} / \mathrm{cm}^{2}$; however, a dose of at least $422 \mathrm{~J} / \mathrm{cm}^{2}$ was needed to kill seeds. This study demonstrated that a strategic burst of intense microwave energy, focused onto the stem of the plant is as effective as applying microwave energy to the whole plant, but uses much less energy.

\section{Introduction}

Interest in the effects of high frequency electromagnetic waves on biological materials dates back to the late 19th century [1], while interest in the effect of high frequency waves on plant material began in the 1920s [1]. More recent studies have been motivated by a growing list of herbicide-resistant biotypes [2] and environmental concerns over herbicide use [3].

Many of the earlier experiments on plant material focused on the effect of radio frequencies (RF) on seeds [1]. In many cases, short exposure resulted in increased germination and vigour of the emerging seedlings [4]; however, long exposure usually resulted in seed death [1]. For example, Headlee [5] observed that exposure to electromagnetic fields in the frequency range between $750 \mathrm{kHz}$ and $3 \mathrm{MHz}$ caused no injury to wheat seeds even after 80 minutes; however, exposure to $5 \mathrm{MHz}$ electromagnetic fields reduced germination to $54 \%$ compared with the control samples which maintained an $88.6 \%$ germination rate. McKinley [6] exposed seeds of Golden Bantam corn to high frequency fields. Seeds were killed after 5 minutes. A one-minute exposure did not kill the seeds, but slightly retarded their germination.
Exposures of 30 to 40 seconds resulted in accelerated growth of the seedlings in their early germination period.

Davis et al. [7, 8] were among the first to study the lethal effect of microwave heating on seeds. They treated seeds, with and without any soil, in a microwave oven and showed that seed damage was mostly influenced by a combination of seed moisture content and the energy absorbed per seed.

Other findings suggested that both the specific mass and specific volume of the seeds were strongly related to a seed's susceptibility to damage by microwave fields [8]. The association between the seed's volume and its susceptibility to microwave treatment may be linked the "radar cross-section" [9] presented by seeds to propagating microwaves. Large radar cross sections allow the seeds to intercept, and, therefore, absorb, more microwave energy.

Several patents dealing with microwave treatment of weeds and their seeds have been registered [10-12]; however, none of these systems appear to have been commercially developed. This may be due to concerns about the energy requirements to manage weed seeds in the soil using microwave energy. In a theoretical argument based on the dielectric and density properties of seeds and soils, Nelson [13] 
demonstrated that using microwaves to selectively heat seeds in the soil "cannot be expected". He concluded that seed susceptibility to damage from microwave treatment is a purely thermal effect, resulting from soil heating and thermal conduction into the seeds. This has been confirmed experimentally by Brodie et al. [14].

Microwave treatment of soil may be useful for niche applications where small areas of soil need to be intensively treated, and soil fumigation is not an option; however, the use of microwaves for killing soil-borne seeds in a broad acre situation may be prohibitively expensive [13]; however, seedlings are many times more susceptible to microwave damage than seeds in the soil $[7,15]$.

Bigu-Del-Blanco et al. [16] exposed 48-hour-old seedlings of Zea mays (var. Golden Bantam) to $9 \mathrm{GHz}$ radiation for 22 to 24 hours. The power density levels were between 10 and $30 \mathrm{~mW} \mathrm{~cm}^{-2}$ at the point of exposure. Temperature increases of only $4^{\circ} \mathrm{C}$, when compared with control seedlings, were measured in the treated specimens. The authors concluded that the long exposure to microwave radiation, even at very low power densities, was sufficient to dehydrate the seedlings and inhibit their development. Rapid dehydration of the plant tissue appears to be the cause of death and growth inhibition. This is because microwave heating results have been coupled with rapid diffusion of moisture [17] through porous materials, which in plants may accelerate moisture loss in spite of the very small rise in plant temperature observed during these trials.

Horn antennas (Figure 1) are popular for microwave communication systems [18]. Horn antennas are also very useful for projecting microwave energy onto objects that cannot be placed inside an enclosed microwave cavity, such as a standard microwave oven.

The vertical plane of the horn antenna is usually referred to as the $E$-plane, because of the orientation of the electrical field (or E-field) in the antenna's aperture. The horizontal plane is referred to as the $H$-plane, because of the orientation of the magnetic field (or $H$-field) of the microwave energy. Typical temperature distributions, created by a pyramidal horn antennas, can be estimated using mathematical equations $[19,20]$. The unique feature of microwave heating is that the maximum temperature is located well below the surface of the heated material (Figure 2).

There is a concern about the effect of microwave treatment on soil biota. Ferriss [21] reported that microwave treatment reduced populations of soil microorganisms with increasing treatment time; however, these effects decreased with increasing amounts of soil and decreased with increasing soil water content between 16 and 37\% (wt. water/dry wt. soil). No pronounced effect of soil type was noted in this experiment. Treatment of $1 \mathrm{~kg}$ of soil, at $7 \%$ to $37 \%$ water content, for $150 \mathrm{~s}$ in a $653 \mathrm{~W}$ microwave oven, operating at $2.45 \mathrm{GHz}$, eliminated populations of Pythium, Fusarium, and all nematodes except Heterodera glycines. Marginal survival of Rhizoctonia, cysts of $H$. glycines, and mycorrhizal fungi was observed in some treated soils. Treatment of $4 \mathrm{~kg}$ of soil for 425 s gave comparable results [21].

In a previously reported experiment using a horn antenna, Cooper and Brodie [22] discovered that microwave

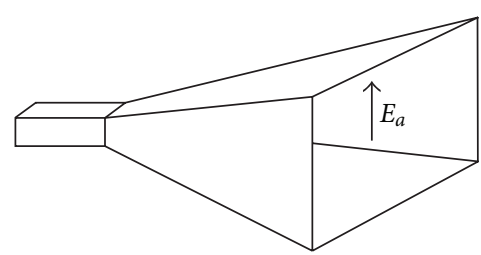

Figure 1: A typical horn antenna showing the orientation of the electrical field component of the microwave energy in the antenna's aperture.

treatment of clay loam soil reduced bacterial populations by $78 \%$ in the top $2 \mathrm{~cm}$ of soil after 16 minutes of microwave treatment; however, populations at $10 \mathrm{~cm}$ depth were not significantly affected by treatment. This study also investigated the effect of microwave heating on key soil nutrients and $\mathrm{pH}$. The findings from this earlier work [22] suggest that microwave treatment of up to 16 minutes will have little effect on soil nutrients and $\mathrm{pH}$ and will not sterilise the soil of bacteria [22]; therefore, treatment durations of a few seconds or minutes are unlikely to change any soil properties.

Two important features of microwave heating in moist materials are (1) simultaneous heat and moisture diffusion through the irradiated material [17] and (2) an uncontrolled temperature increase called "thermal runaway" [23-25].

Plant materials with large moisture content have greater dielectric constants (Figure 3). As plant materials dry during microwave heating, their dielectric properties change significantly. These changes are too slow to affect individual cycles of the microwave fields; however, they affect microwave heating on the much longer thermal time scale.

The effect of changing dielectric properties on microwave heating can be studied using mathematical equations for microwave heating [20] and equations for the dielectric properties of the plant materials [26]. The heating rate for $10 \mathrm{~mm}$ and $12 \mathrm{~mm}$ diameter cylinders of plant material is relatively constant with time (Figure 4 ); however, there is a sudden $80^{\circ} \mathrm{C}$ jump in the $15 \mathrm{~mm}$ diameter case at 5 seconds of microwave heating when there is no change in the applied microwave power (Figure 4). This sudden jump in temperature is the result of "thermal runaway".

Vriezinga has studied this phenomenon and concluded that thermal runaway is caused by (1) the specific characteristic of the dielectric loss factor of water, which decreases with increasing temperature [27] and (2) resonance of the electromagnetic waves within the irradiated medium due to changes in the electromagnetic wavelength inside the irradiated medium as the dielectric properties change during heating $[27,28]$. Resonance will only occur when the object's dimensions are similar to the wave length of the microwave fields inside the object. That is why thermal runaway only becomes evident in the $15 \mathrm{~mm}$ diameter stem (Figure 4), while the smaller stems are too narrow to allow field resonance.

In most cases, thermal runaway is a problem during microwave heating. It usually leads to undesirable destruction of the microwave-heated material [29]; however, it has been very effectively used in applications such as the microwave 


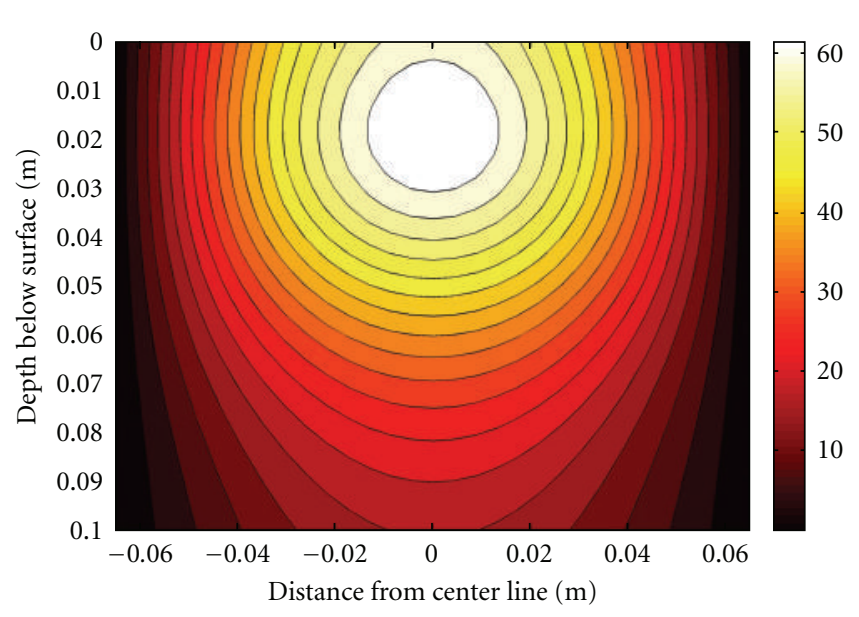

(a)

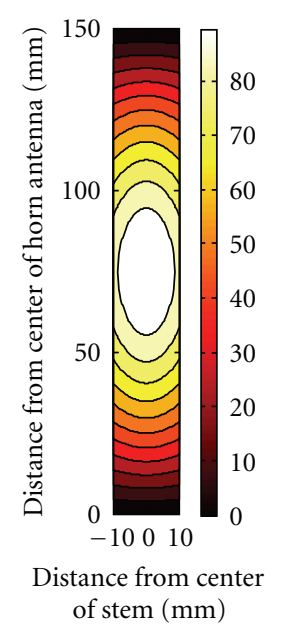

(b)

Figure 2: Typical temperature distribution created by a pyramidal horn with aperture dimensions of $130 \mathrm{~mm}$ by $43 \mathrm{~mm}$ and a length of $100 \mathrm{~mm}$ in soil profile (a) and the cross section of a $10 \mathrm{~mm}$ thick plant stem (b) calculated using equations presented in [20]. (Note: the temperature scales are in $\left.{ }^{\circ} \mathrm{C}\right)$.

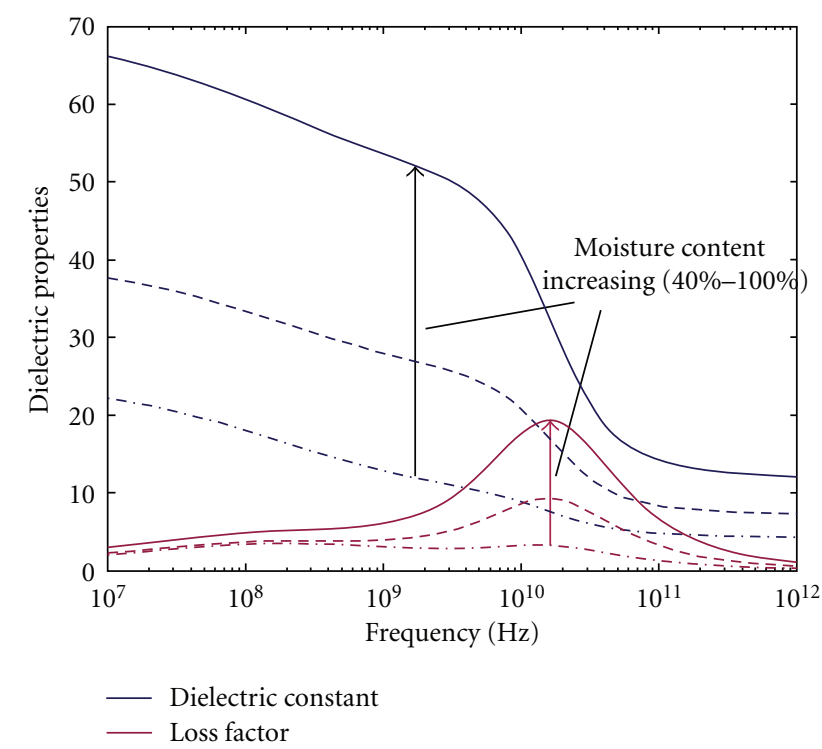

FIGURE 3: Dielectric properties of plant materials as a function of frequency and moisture content.

drill [30, 31], which can drill holes through ceramics by superheating a very small section of the material. In the case of weeds, sudden destruction of the plant tissue due to microwave-induced thermal runaway will be very desirable.

Cucumis myriocarpus is an annual prostrate vine belonging to the family Cucurbitaceae that is native to southern Africa [32]. Cucumis myriocarpus has multiple stems that can grow up to $1.6 \mathrm{~m}$ long and produces fruit in the form of small spiky yellow-green or green-striped melons that are approximately $20-25 \mathrm{~mm}$ in diameter. These melons contain many seeds that are 3.5-4 mm long [33]. The fruit and foliage are toxic due to the presence of cucurbitacin, which is a cytotoxic steroid produced by the plant as a defence against herbivores [32]. The plant has been known to kill livestock

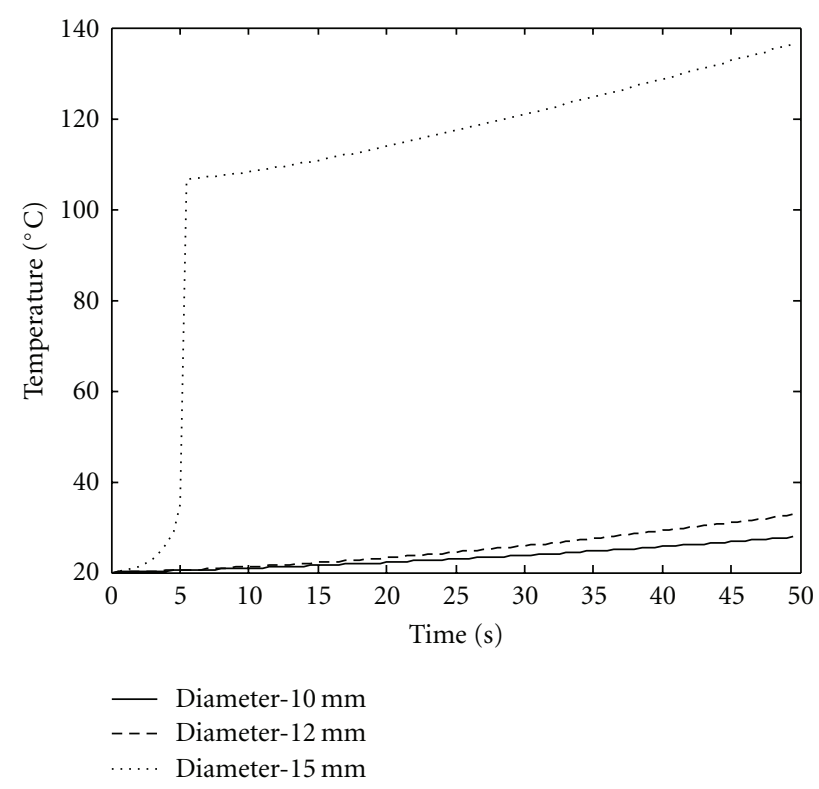

FIgURE 4: Temperature response, at a constant microwave power density, in the centre of a cylinder of plant-based material, as a function of plant stem diameter, assuming a constant moisture loss from a moisture content of 0.87 to 0.10 during microwave heating.

[32]. Cucumis myriocarpus is a weed in Australia and in California, where it may also be known as prickly paddy melon, bitter apple, and gooseberry gourd [32]. The plant also occurs in Spain, where it is known by the common names of "habanera" or "sandia habanera" [32].

Cucumis myriocarpus germinates in spring or early summer depending on rainfall. They have the ability to germinate over an extended period particularly if soil disturbance occurs [19]. Growth can be rapid if moisture is adequate and plants can quickly establish a substantial tap root [29]. Established plants produce new growth from the large crown 
in spring to early summer with trailing branches or vines, growing rapidly in the summer months with a single mature plant being able to occupy an area of up to $7 \mathrm{~m}^{2}$ [33]. Plants normally flower and fruit in mid to late summer and growth can progress well into autumn if the weather is warm. Chemicals are commonly used for summer weed control, but Leys et al. [30] have found that Cucumis myriocarpus is very tolerant of glyphosate [30]. Resistance to other herbicides may develop as it has in other species [31]; therefore, it is important to explore alternative methods of weed management before conventional options fail. The objective of this study was to explore the effect of microwave energy on prickly paddy melon (Cucumis myriocarpus) plants and seeds.

\section{Method}

2.1. Study Strategy. This study was subdivided into a series of separate but linked experiments that investigated the effect of microwave treatment on paddy melon plants, fruits, and seeds. Some experiments were completed in the field using a prototype microwave system (Figure 5), energised from the magnetron of a microwave oven, operating at $2.45 \mathrm{GHz}$. It had an $86 \mathrm{~mm}$ by $43 \mathrm{~mm}$ rectangular wave-guide channeling the microwaves from the oven's magnetron to a horn antenna outside of the oven.

The horn antenna allowed microwave energy to be focused onto sample plants in pots and in situ, while the oven's timing and power circuitry was used to control the activity of the magnetron. Other experiments in this study were completed using a standard microwave oven, also operating at $2.45 \mathrm{GHz}$.

Therefore, two pyramidal horn applicators (Figure 6), with varying aperture dimensions $(130 \mathrm{~mm}$ by $43 \mathrm{~mm}$ and $86 \mathrm{~mm}$ by $20 \mathrm{~mm}$ ), were developed and tested during these experiments.

2.2. Calibration Tests. The deliverable power from a microwave system depends on many parameters including the impedance match between all the components of the waveguide system. In this case, no attempt to match the impedance along the wave-guide was made; therefore, the delivered microwave power was determined experimentally so that energy analyses could be conducted.

The deliverable microwave power can be determined using two samples of water. One acts as a control to determine the energy balance associated with the ambient conditions, while the other is heated by the microwave system. The power absorbed by the treated water sample $\left(P_{a}\right)$ can be calculated from the combination of sensible and latent heat observed in the two samples using the following equation:

$$
\begin{aligned}
& P_{a} \\
& =\frac{\left\{\left(4.18 \Delta T_{m}+\frac{2260 \Delta m_{m}}{m_{m}}\right)-\left(4.18 \Delta T_{c}+\frac{2260 \Delta m_{c}}{m_{c}}\right)\right\} m_{m}}{\tau \times t_{h}} .
\end{aligned}
$$

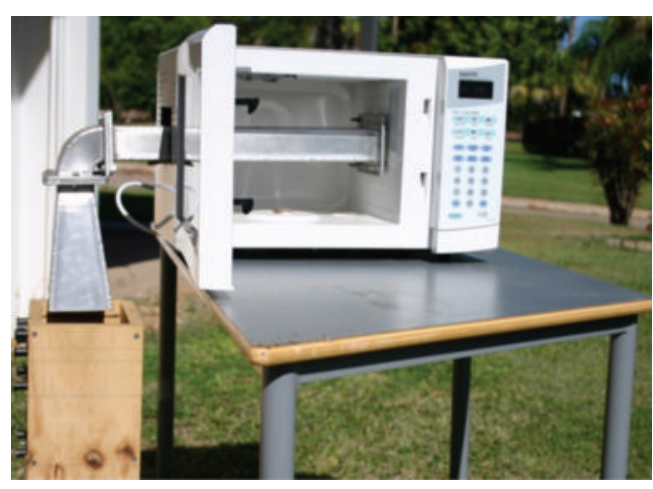

Figure 5: A laboratory prototype system based on a modified microwave oven.

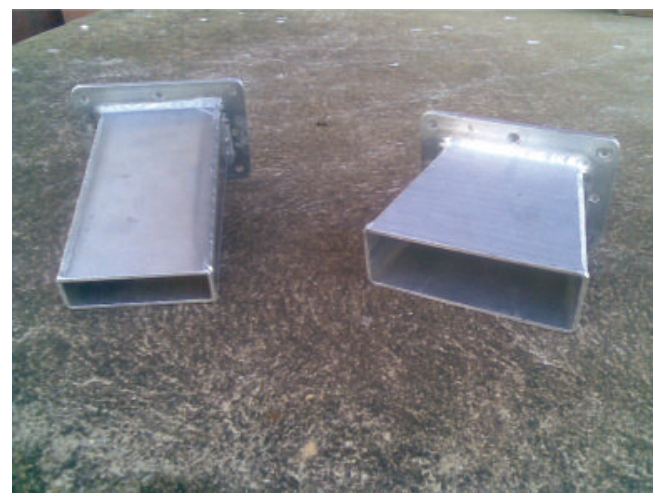

FIGURE 6: Horn antennas used in these microwave experiments.

The water in the treated sample will reflect some microwave energy from its surface. The portion of the microwave energy that is transmitted through the water surface $(\tau)$ is determined by the dielectric properties of the air and water at their interface:

$$
\tau=\frac{2 \sqrt{\varepsilon_{a}}}{\sqrt{\varepsilon_{a}}+\sqrt{\varepsilon_{w}}} .
$$

The microwave oven used in the prototype has a nominal rating of $750 \mathrm{~W}$; however, the delivered power may be much less than this due to internal reflections in the magnetron coupling antenna that feeds the energy into the wave guide. The system was calibrated using water at $19^{\circ} \mathrm{C}$. Three calibration runs were used to determine the output power of the system.

Water at $19^{\circ} \mathrm{C}$ has a complex dielectric constant of 78.9$j 11.0$, and air has a dielectric constant of $1+j 0$. Therefore, the transmission coefficient at the water surface was 0.2 . The prototype oven was producing an average output power of $541.3 \mathrm{~W}$.

This calibration procedure was also applied to a microwave oven that was used in Experiments 3 and 4 described later in this section. The calibration procedure revealed that the microwave oven was producing an average output power of 644.4 W. 
Experiment 1 (Microwave Treatment of Potted Paddy Melon). Paddy melon plants, with 10-20 fully opened leaves, were collected from a field site near the township of St James, Victoria, Australia ( $36^{\circ} 17^{\prime} \mathrm{S}$ Latitude and $145^{\circ} 53^{\prime}$ East Longitude) and transplanted into $13 \mathrm{~cm}$ pots with two plants in each pot. The pots were filled with commercial potting mix. Plants were watered every 2 or 3 days for 7 days to allow recovery from transplanting.

Each plant was individually exposed to microwave energy. The microwave energy was directed onto the plants using one of the horn antennas, depending on the particular treatment being applied. The experiment was set up as a 2 by 5 factor randomised design, where Factor $A$ was the two different horn antenna designs and Factor $\mathrm{B}$ was the exposure time $(0,5,15,30$, and 60 seconds). Each treatment combination was applied to 10 plants, with each plant acting as an individual replicate. The second plant in the treated pot was shielded from microwave energy during treatment using aluminium foil.

Radiation measurements, using a hand held microwave leakage detector, revealed that the magnetron of the microwave oven took approximately 3 seconds from initial power up to begin generating microwave energy. Therefore, an additional 3 seconds was added to the treatment times. For example, to achieve 5 seconds of microwave treatment, the microwave oven's timer was set to 8 seconds to allow for this starting delay.

All plants were placed in a sunlit area and watered every 2 or 3 days to maintain the potting mix at field moisture capacity. Eleven days after treatment, the plants were evaluated to estimate the portion of the plant's foliage and stem tissue that was either unaffected or had recovered from the microwave treatment, with the data being expressed as a fraction of the whole plant (i.e., a value of 0.25 indicated that $25 \%$ of the plant's foliage and stem tissue appeared to be healthy 11 days after treatment). The resulting data was analysed using a 2 by 5 factor Friedman analysis of variance. The Friedman analysis of variance is a nonparametric variation of the analysis of variance that can analyse data that is continuous but not necessarily normally distributed [34].

Experiment 2 (Microwave Treatment of Paddy Melon in the Field). Paddy melon is a multistemmed prostrate plant where individual plants can have an effective surface area of several square metres. It could be far too energy expensive to treat the entire plant [13]. The motivating interest in Experiment 2 was to determine whether focusing microwave energy onto a small section of the plant's stem could effectively kill the rest of the stem beyond the point of treatment.

Two sites were selected for this experiment; one site was near the township of St James, where the potted samples for Experiment 1 were sourced, and the other site was at the Dookie Campus of The University of Melbourne ( $36^{\circ} 23^{\prime} \mathrm{S}$ Latitude and $145^{\circ} 42^{\prime}$ East Longitude).

Twenty paddy melon plants, with 30-50 fully opened leaves, were randomly selected at each site and treated using the small aperture horn antenna attached to the prototype microwave system. The applied treatments were 5, 10, 15, 30, and 60 seconds of microwave exposure. Four control plants were also labelled at each site. The treatment that each plant received was identified using metal tags on pegs driven into the soil adjacent to each plant. All plants at both sites were assessed in the same fashion as the potted plants 16 days after treatment. The resulting data was analysed using a single factor Kruskal-Wallis analysis of variance, with the treatment factor being microwave exposure time. The Kruskal-Wallis analysis of variance is another nonparametric variation of the analysis of variance that can analyse data that is not normally distributed [34].

Experiment 3 (Microscopic Analysis). The purpose of this experiment was to determine if there was any obvious cellular damage created in the treated plant that could be attributed to microwave irradiation. Paddy melon plants, with 10-20 fully opened leaves, were collected from the field at the Dookie Campus site and transplanted into pots using the same arrangements as in Experiment 1. After acclimation in the pots for 5 days, two of the plants were selected at random and treated for 5 seconds using the small aperture horn antenna. After another 5 days, two of the remaining untreated plants were randomly selected and carefully removed from the pots to ensure that the root material was removed with the plant. The roots were washed to remove any potting mix.

One of the plants from the second selection was randomly selected to be the control plant, and the other plant from the second selection was treated in a standard microwave oven, operating at $2.45 \mathrm{GHz}$, for 5 seconds. A leaf stem on each plant was selected for microscopic comparisons. The stems were of similar sizes and the selected leaf stem on each plant was marked with a black marker for easy identification after treatment.

Three cross-sections of the selected leaf stem, a few cell lengths thick, were shaved from the stem using a sharp razor blade. These sections were mounted on a microscope slide. For comparison, three cross-sections from the control plant's leaf stem were also cut and mounted on the same microscope slide next to the freshly treated cross-sections.

After selecting a different leaf stem on each plant, the freshly treated plant was placed in the microwave oven again and treated for a further five seconds, before another three cross-sections were cut and mounted onto the slide. This process was repeated for a third time, so that the slide contained three different treatments $(5,5+5$ and $5+5+5$ seconds) with cross-sections from the control plant near each treated sample for easier comparison; however, the discontinuous treatments imposed on these samples may not have the same effect as continuous treatments of the same total time duration.

A dye, made from a mixture of dilute Fuchin 1\% Phenol $5 \%$ and Methylene Blue 1\%, was used to highlight the cell structures in the stems.

Sections of plant stem that were treated using the small aperture horn antenna 5 days earlier were also examined. Sections were taken from part of the stem that was clearly affected by the microwave treatment and other sections were taken from the same stem in areas that were not directly 
affected by microwave treatment. Microscope slides were prepared using the same process as described above.

Microscopic examination of the cross-sections was performed using a dissecting microscope with a video camera attached to the eye piece. Unfortunately, the video equipment did not allow image capture, so photographs of the crosssections were captured from the video display using a 2 MPixel digital camera.

Experiment 4 (Seed Viability Testing). Paddy melon seeds, collected from the Dookie Campus field site, were treated in the same microwave oven that was used in Experiment 3. There were six microwave treatment groups plus two untreated groups of seeds. Three of the treatments involved extracting the seeds from ripe melons and treating them on a microwave-resistant dish. These seeds were exposed to $644.4 \mathrm{~W}$ of microwave power for 10, 20, or 30 seconds.

Three other treatments involved treating whole melons for 10, 20, or 30 seconds. Melons were placed in a beaker and exposed to microwave energy for the prescribed amount of time. The seeds were extracted from the melons after they had cooled. One set of melons was left untreated. There were approximately sixty seeds in each of the eight treatment groups.

Using a scalpel, under a dissecting microscope, a small sliver of the seed coat was cut from each seed to reveal the seed kernel. The seeds were then soaked in 1\% 2, 3, 5 Triphenyl Tetrazolium Chloride and placed in an incubator at $35^{\circ} \mathrm{C}$.

After 18 hours, the seeds were removed from the incubator and, using a scalpel under a dissecting microscope, the seeds were cut in half. Seeds were assessed as being viable; nonviable; or having uncertain viability, depending on the completeness of seed staining caused by the Tetrazolium [35].

Seeds that were fully stained were assessed as being viable and allocated a viability score of 1.0. Seeds that had no staining were assessed as being nonviable and allocated a viability score of 0.0. Some seeds were only partially stained, so these were classed as having uncertain viability and allocated a viability score of 0.5 .

The resulting seed viability data was analysed using a single factor analysis of variance. The resulting data was analysed using a 2 by 3 factor Friedman two-way analysis of variance, where Factor $A$ was whether the seeds were in the melons or free from the melons during treatment and Factor $\mathrm{B}$ was the microwave exposure time ( $0 \mathrm{~s}, 10 \mathrm{~s}, 20 \mathrm{~s}$, or $30 \mathrm{~s})$.

Additional 20 fruits were randomly selected from the field site at Dookie Campus. These were weighed and had their three major diameters measured using callipers. This data was used to calculate energy density requirements to effectively treat the seeds in the fruit. Energy density can be estimated by assuming that all of the microwave energy in the chamber is absorbed by the fruit. Therefore, the energy per fruit is given by

$$
E_{f}=\frac{P \times t_{h}}{N} .
$$

Similarly, the energy density as a function of fruit crosssectional area can be calculated using

$$
E_{A}=\frac{P \times t_{h}}{A} .
$$

Microwave energy density was calculated for each of the treatments used in Experiments 1 and 2. The data from all treatments was pooled in terms of this energy density to determine a dose response curve for paddy melon plants. The probability of survival can be described by

$$
P_{\text {survival }}=\frac{1.0}{1+\left(\psi / D_{50}\right)^{20}} \text {. }
$$

\section{Results}

Experiment 1. Microwave heating affected the melon plants quickly. Audible clicking sounds emanated from the plant during the treatment process. It was also possible to see the plant wilt during the first 10 to 15 seconds of treatment when the antenna with the larger aperture was used (Figure 7). The only visible difference in the plants induced by microwave treatment was drooping of the leaves. The small aperture antenna caused much louder acoustic emissions and visible rupture of the plant stems (Figure 8) within a few seconds of initial microwave treatment. In the case of the larger aperture antenna, increasing treatment time significantly reduces survival of the plants (Table 1). Using the antenna with the smaller aperture killed all the paddy melon plants for all treatment times.

Experiment 2. The control plants at both field sites had grown during the 16-day interval between applying the microwave treatments at the site and the evaluation of results. All treated plants at both sites, irrespective of the treatment duration, died. Therefore, these results were the same as those listed for the small aperture antenna in Table 1. This confirms that microwave treatment is effective in the field as well as in the more controlled situation where potted plants were used.

Experiment 3. The microscopic images of the freshly treated plant material (Figure 9) showed no obvious signs of cellular rupture due to microwave treatment, and no other obvious differences in cell structure could be seen between the control plant samples and the microwave-treated plant (Figure 9); however, at the macroscopic level the microwave treated plant had wilted during treatment.

For plants that were treated with microwave energy from the small aperture horn antenna five days prior to examination, no obvious cell structures were visible in the section of stem that was affected by microwave treatment (Figure 10(b)); however, some cell structures were visible in the unaffected section of the same leaf stem (Figure 10(a)). This suggests that the cells in the affected section of the stem have completely collapsed due to microwave treatment. 


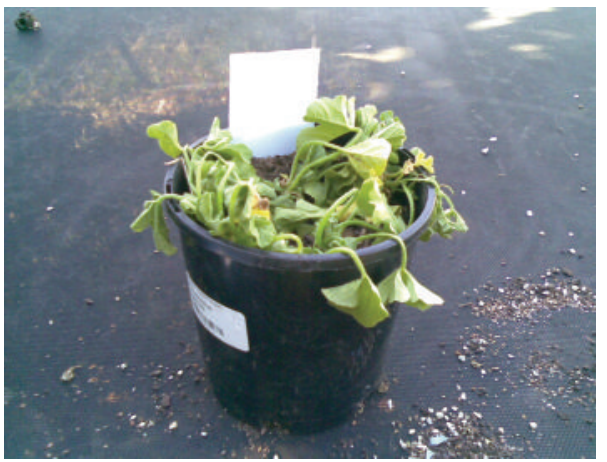

(a)

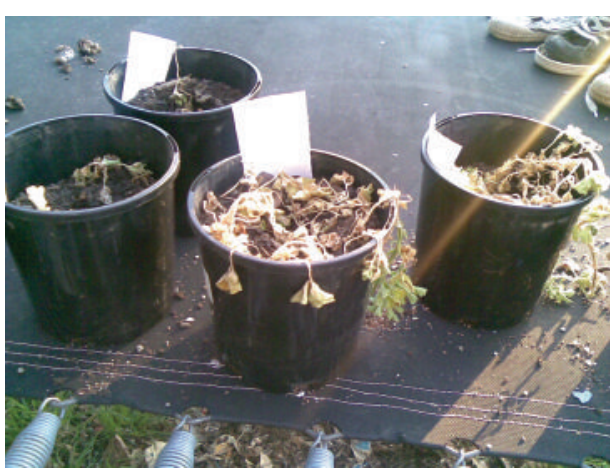

(b)

FIGURE 7: Paddy melon plants (a) immediately after microwave treatment for 15 seconds and (b) 11 days after treatment.

TABLE 1: Mean percentage of unaffected or recovered paddy melon plants according to treatment combination.

\begin{tabular}{lcccccc}
\hline \multirow{2}{*}{ Antenna design } & \multicolumn{5}{c}{ Treatment time $(\mathrm{s})$} \\
& 0 & 5 & 10 & 15 & 30 & 60 \\
\hline Large aperture & $100 \%^{\mathrm{a}}$ & $100 \%^{\mathrm{a}}$ & $100 \%^{\mathrm{a}}$ & $60 \%^{\mathrm{b}}$ & $0 \%^{\mathrm{c}}$ & $0 \%^{\mathrm{c}}$ \\
Small aperture & $100 \%^{\mathrm{a}}$ & $0 \%^{\mathrm{c}}$ & $0 \%^{\mathrm{c}}$ & $0 \%^{\mathrm{c}}$ & $0 \%^{\mathrm{c}}$ \\
\hline
\end{tabular}

Note: Means with different superscripts are significantly different from one another.

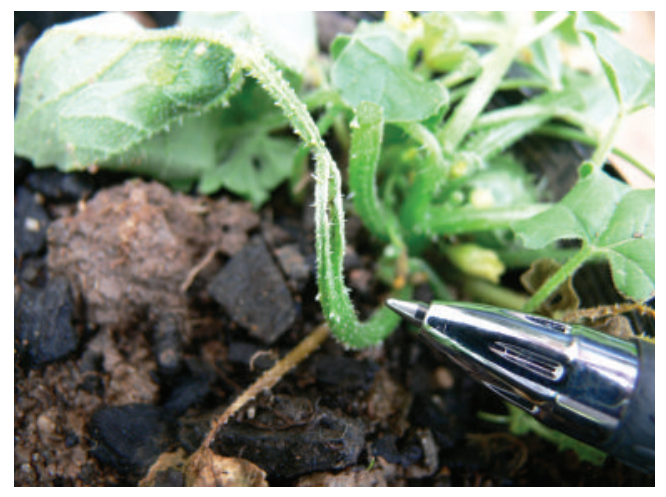

FIGURE 8: Section of plant stem ruptured during microwave treatment using the small aperture antenna.

Experiment 4. There was no significant difference in seed survival between the various microwave treatment combinations, compared with each other; however, all combinations of microwave treatment had a significant effect on seed survival compared with the controls. Based on data from Experiments 1 and 2, the half lethal microwave energy dose, across all treatments, was $145 \mathrm{~J} \mathrm{~cm}^{-2}$ (Figure 11).

\section{Discussion}

Microwave treatment kills paddy melon plants and seeds (Tables 1 and 2). Although there is no immediate evidence of plant cell damage (Figure 9) during microwave treatment that is not intense enough to cause localised steam explosions in the stem (Figure 8), there must be a mechanism that causes the stems to collapse (Figure 10) leading to permanent wilting and death of the plant stem within a few days (Figure 7).

Unlike conventional heating, microwave heating produces its highest temperature in the core of the plant stem (Figure 3). Water in the xylem tissue is usually under tensile stresses [36]. The high core temperatures associated with microwave heating may lead to cavitation in the waterfilled xylem tissue [36]. This may account for the acoustic emissions from the plant during microwave treatment. Extensive cavitation in the xylem tissue may lead to irrecoverable embolisms that block sap flow and ultimately lead to permanent wilting and death of the stem (Figure 7). In extreme cases, there may also be cell rupture due to localised steam explosions inside the stem (Figure 8).

The temperature inside the plant's stem (5) depends on the strength of the microwave's electric field $(E)$ and the dielectric properties of the plant material. The small aperture antenna often caused stem rupture within the first few seconds of microwave treatment because the temperature inside the core of the stem may have been sufficient to create steam inside the plant cells. Thus a strategically applied short burst of intense microwave energy onto the plant's stem was sufficient to kill the plants (Table 1). This is because microwave heating is proportional to the square of the electric field strength. Very intense microwave fields have also been linked to thermal runaway.

The dose response curve (Figure 11) indicates that 100\% control of paddy melon should be achieved using $200 \mathrm{~J} \mathrm{~cm}^{-2}$ (or $20 \mathrm{GJ} \mathrm{ha}^{-1}$ ) of microwave energy. In a study of various cropping systems by Mari and Chengying [37] estimated 


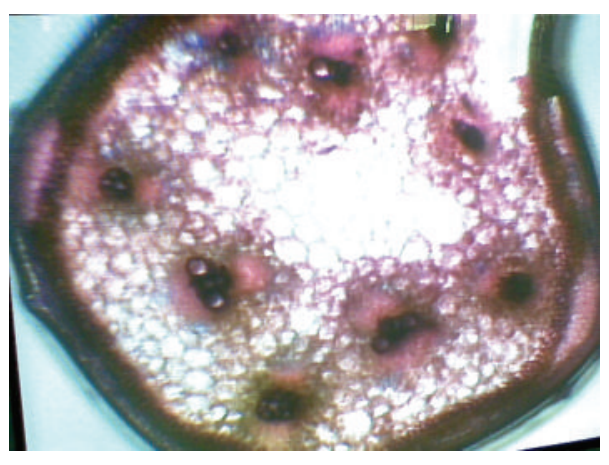

(a)

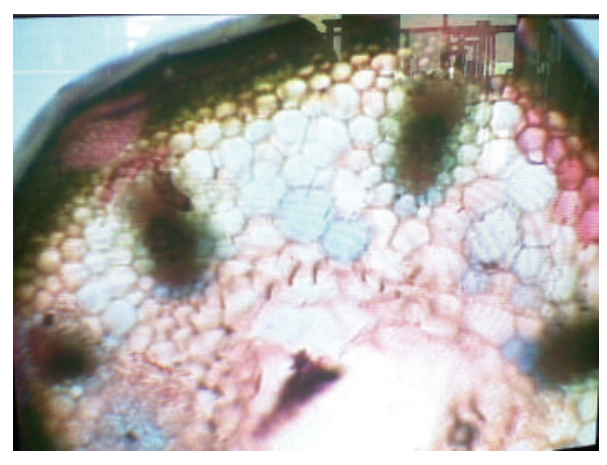

(b)

FIGURE 9: Comparison of stem cross-sections for (a) fresh untreated plant and (b) a plant after 15 seconds of treatment.

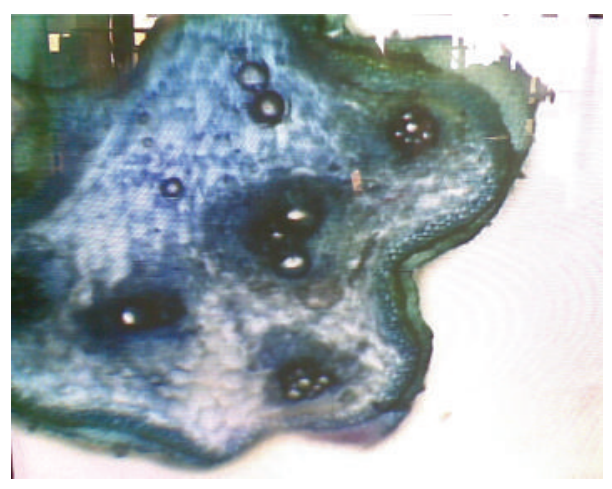

(a)

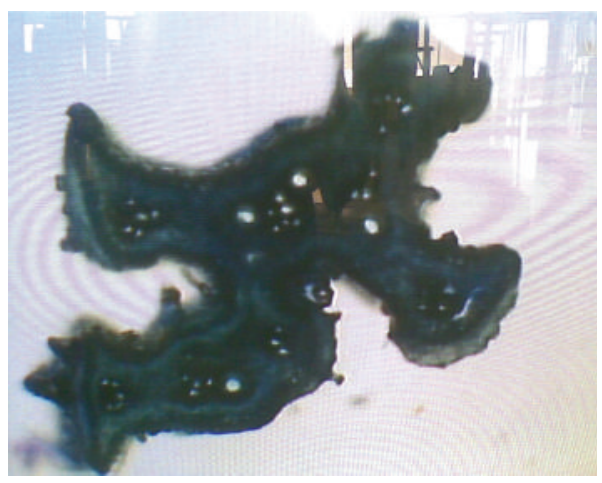

(b)

Figure 10: Comparison of stem cross-sections for (a) unaffected part of microwave-treated plant and (b) a part of the same stem affected by 10 seconds of microwave treatment using the small aperture horn antenna (microscopic observations made 5 days after microwave treatment).

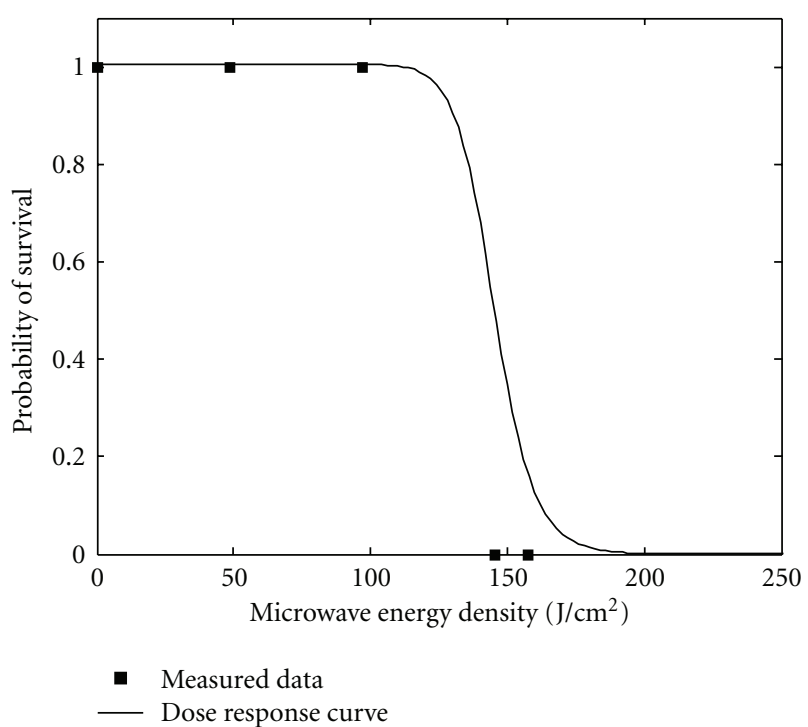

FIGURE 11: Microwave energy density dose response curve for paddy melon plants. that the embodied energy of herbicide usage, which included manufacture, transport, and application, was $2.2 \mathrm{GJ} \mathrm{ha}^{-1}$; therefore, uniformly applied microwave treatment is an order of magnitude higher than the embodied energy associated with chemical plant protection [37-39].

A strategic burst of intense energy, focused onto the stem of the plant, is as effective as, but much quicker at treating the plant, than an application of microwave energy to the whole plant. This may be of great interest for controlling chemically resistant Paddy Melon plants [30]. For example, if the microwave field from a travelling microwave weed control system cuts across any of the prostrate stems of a Paddy Melon plant, this research has demonstrated that the stem tissue beyond the point of treatment should die within a few days of treatment.

If a mature plant has an average of 5 long stems and is assumed to occupy an area of $7 \mathrm{~m}^{2}$, as mentioned earlier, then a 5-second burst of microwave energy from the small aperture horn antenna, applied to each of the 5 stems near the crown of the plant, equates to an energy density of $0.2 \mathrm{~J} \mathrm{~cm}^{-2}$ ( or $0.02 \mathrm{GJ} \mathrm{ha}^{-1}$ ) over the whole area of the plant. 
TABLE 2: Mean fraction of paddy melon seeds that survived microwave treatment.

\begin{tabular}{|c|c|c|c|c|}
\hline \multirow{2}{*}{ Seed condition } & \multicolumn{4}{|c|}{ Microwave treatment } \\
\hline & Control & $10 \mathrm{sec}$ & $20 \mathrm{sec}$ & $30 \mathrm{sec}$ \\
\hline Seeds in melons & $0.79^{\mathrm{a}}$ & $0.20^{\mathrm{b}}$ & $0.18^{\mathrm{b}}$ & $0.07^{b}$ \\
\hline Free seeds & $0.81^{\mathrm{a}}$ & $0.18^{\mathrm{b}}$ & $0.15^{\mathrm{b}}$ & $0.19^{\mathrm{b}}$ \\
\hline
\end{tabular}

$\operatorname{LSD}(P=0.05): 0.27$

Note: Means with different superscripts are significantly different from one another.

The practicalities of applying microwave energy to the stems of plants have yet to be determined; however, various remote sensing systems that strategically apply chemical treatments to individual plants already exist [40]. Eventually, these systems may be adapted to apply microwave energy onto the stems of individual plants.

"Scale up" calculations in microwave heating systems are difficult to discuss because they are notoriously nonlinear. This is due to the nonlinear temperature/microwave field strength relationships, redistribution of energy associated with the coupling of heat and moisture movement [17], and phenomena such as thermal runaway, which all occur when the applied microwave power is increased. Other impediments to using microwave energy for controlling weeds in the field include nonuniform energy distributions in the microwave fields; protection of operators from microwave field leakage; loss of microwave energy due to transmission through the soil, beyond the treated plants.

Microwave treatment also reduced paddy melon seed viability by between $60 \%$ and $70 \%$ (Table 2); however, analysis of the microwave energy used during the 10 second treatment inside the microwave oven revealed that the melons were exposed to approximately $1610 \mathrm{~J} /$ fruit. In terms of energy density over the minimal projected area of the fruit, this equates to $422 \mathrm{~J} / \mathrm{cm}^{2}$, which is twice the energy density needed to kill the parent plants. This is consistent with other studies $[7,15]$, which show that plants are more susceptible to microwave damage than seeds [15].

If thermal runaway can be induced in plant tissues, fruits, and seeds, treatment time and the associated treatment energy may be drastically reduced for a small increase in applied microwave field density. This would make microwave treatment energy comparable with the embodied energy in chemical systems; however, this can only be explored by further research using a more powerful prototype system.

\section{Conclusion}

Microwave treatment kills paddy melon plants and significantly reduces the number of viable seeds.

\section{Nomenclature}

$\psi: \quad$ Microwave energy density $\left(\mathrm{J} \mathrm{cm}^{-2}\right)$

A: Cross-sectional area of melon fruit

$$
A=\pi \times r_{1} \times r_{2}\left(\mathrm{~m}^{2}\right)
$$

$D_{50}$ : Half lethal dose

$m_{c}$ : Initial masses of the control samples $(\mathrm{kg})$ $m_{m}: \quad$ Initial masses of the microwave-treated samples ( $\mathrm{kg}$ )

$N: \quad$ Number of treated fruit

$P: \quad$ Applied microwave power (W)

$t_{h}$ : Microwave heating time for experiment (s)

$\Delta m_{c}$ : Changes in mass of the control samples $(\mathrm{kg})$

$\Delta m_{m}$ : Changes in mass of the microwave-treated samples $(\mathrm{kg})$

$\Delta T_{c} \quad$ Change in temperature of the control samples $(\mathrm{K})$

$\Delta T_{m}$ : Change in temperature of the microwave-treated samples $(\mathrm{K})$

$\varepsilon_{a}: \quad$ Complex dielectric constant of air

$\varepsilon_{w}$ : Complex dielectric constant of water

$\tau: \quad$ Transmission coefficient for the transfer of microwave energy into the material.

\section{Acknowledgments}

The authors thank the Grains Research and Development Corporation (GRDC) and the Rural Industries Research and Development Corporation (RIRDC) for their generous financial support during this study.

\section{References}

[1] P. A. Ark and W. Parry, "Application of high-frequency electrostatic fields in agriculture," The Quarterly Review of Biology, vol. 15, no. 2, pp. 172-191, 1940.

[2] I. M. Heap, "The occurrence of herbicide-resistant weeds worldwide," Pesticide Science, vol. 51, no. 3, pp. 235-243, 1997.

[3] I. Sartorato, G. Zanin, C. Baldoin, and C. De Zanche, "Observations on the potential of microwaves for weed control," Weed Research, vol. 46, no. 1, pp. 1-9, 2006.

[4] V. N. Tran, "Effects of microwave energy on the strophiole, seed coat and germination of acacia seeds," Australian Journal of Plant Physiology, vol. 6, no. 3, pp. 277-287, 1979.

[5] T. J. Headlee, "The difference between the effect of radio waves on insects and on plants," Journal of Economic Entomology, vol. 24, no. 2, pp. 427-437, 1931.

[6] G. M. McKinley, "Some biological effects of high-frequency electrostatic fields," Proceedings of the Pennsylvania Academy of Science, vol. 4, pp. 43-46, 1930.

[7] F. S. Davis, J. R. Wayland, and M. G. Merkle, "Ultrahighfrequency electromagnetic fields for weed control: phytotoxicity and selectivity," Science, vol. 173, no. 3996, pp. 535-537, 1971.

[8] F. S. Davis, J. R. Wayland, and M. G. Merkle, "Phytotoxicity of a UHF electromagnetic field," Nature, vol. 241, no. 5387, pp. 291-292, 1973. 
[9] W. W. Wolf, C. R. Vaughn, R. Harris, and G. M. Loper, "Insect radar cross-sections for aerial density measurements and target classification," Transactions of the American Society of Agricultural Engineers, vol. 36, no. 3, pp. 949-954, 1993.

[10] H. E. Haller, "Microwave Energy Applicator," patent, 2002/ 0090268A1, 20020090268A1, United States, 2002.

[11] W. J. Clark and C. W. Kissell, "System and Method for In Situ Soil Sterilization, Insect Extermination and Weed Killing," patent, 2003/0215354A1, 20030215354A1, United States, 2003.

[12] G. R. Grigorov, "Method and System for Exterminating Pests, Weeds and Pathogens," patent, 20030037482A1, 20030037482A1, United States, 2003.

[13] S. O. Nelson, "A review and assessment of microwave energy for soil treatment to control pests," Transactions of the American Society of Agricultural Engineers, vol. 39, no. 1, pp. 281289, 1996.

[14] G. Brodie, C. Botta, and J. Woodworth, "Preliminary investigation into microwave soil pasteurization using wheat as a test species," Plant Protection Quarterly, vol. 22, no. 2, pp. 72-75, 2007.

[15] G. Brodie, S. Hamilton, and J. Woodworth, "An assessment of microwave soil pasteurization for killing seeds and weeds," Plant Protection Quarterly, vol. 22, no. 4, pp. 143-149, 2007.

[16] J. Bigu-Del-Blanco, J. M. Bristow, and C. Romero-Sierra, "Effects of low level microwave radiation on germination and growth rate in corn seeds," Proceedings of the IEEE, vol. 65, no. 7, pp. 1086-1088, 1977.

[17] G. Brodie, "Simultaneous heat and moisture diffusion during microwave heating of moist wood," Applied Engineering in Agriculture, vol. 23, no. 2, pp. 179-187, 2007.

[18] F. R. Connor, Antennas, Edward Arnold, London, UK, 1972.

[19] G. I. Brodie, "The influence of load geometry on temperature distribution during microwave heating," Transactions of the American Society of Agricultural and Biological Engineers, vol. 51, no. 4, pp. 1401-1413, 2008.

[20] G. Brodie, "Microwave heating in moist materials," in Advances in Induction and Microwave Heating of Mineral and Organic Materials, pp. 553-584, InTech, Vienna, Austria, 2011.

[21] R. S. Ferriss, "Effects of microwave oven treatment on microorganisms in soil," Phytopathology, vol. 74, no. 1, pp. 121126, 1984.

[22] A. Cooper and G. Brodie, "The effect of microwave radiation on key soil parameters," Plant Protection Quarterly, vol. 24, no. 2, pp. 67-70, 2009.

[23] C. A. Vriezinga, "Thermal runaway and bistability in microwave heated isothermal slabs," Journal of Applied Physics, vol. 79, no. 3, pp. 1779-1783, 1996.

[24] P. E. Parris and V. M. Kenkre, "Thermal runaway in ceramics arising from the temperature dependence of the thermal conductivity," Physica Status Solidi B, vol. 200, no. 1, pp. 3947, 1997.

[25] M. J. Ward, "Thermal runaway and microwave heating in thin cylindrical domains," IMA Journal of Applied Mathematics, vol. 67, no. 2, pp. 177-200, 2002.

[26] F. T. Ulaby and M. A. El-Rayes, "Microwave dielectric spectrum of vegetation: part II: dual-dispersion model," IEEE Transactions on Geoscience and Remote Sensing, vol. GE-25, no. 5, pp. 550-557, 1987.

[27] C. A. Vriezinga, "Thermal profiles and thermal runaway in microwave heated slabs," Journal of Applied Physics, vol. 85, no. 7, pp. 3774-3779, 1999.
[28] C. A. Vriezinga, S. Sánchez-Pedreno, and J. Grasman, "Thermal runaway in microwave heating: a mathematical analysis," Applied Mathematical Modelling, vol. 26, no. 11, pp. 10291038, 2002.

[29] J. Borger and R. Madin, Paddy and Afghan Melons, Department of Agriculture Western Australia, Perth, Australia, 2005.

[30] A. R. Leys, R. L. Amor, A. G. Barnett, and B. Plater, "Evaluation of herbicides for control of summer-growing weeds on fallows in south-eastern Australia," Australian Journal of Experimental Agriculture, vol. 30, no. 2, pp. 271-279, 1990.

[31] Q. Yu, A. Cairns, and S. Powles, "Glyphosate, paraquat and ACCase multiple herbicide resistance evolved in a Lolium rigidum biotype," Planta, vol. 225, no. 2, pp. 499-513, 2007.

[32] R. A. McKenzie, R. D. Newman, A. C. Rayner, and P. J. Dunster, "Prickly paddy melon (Cucumis myriocarpus) poisoning of cattle," Australian Veterinary Journal, vol. 65, no. 6, pp. 167$170,1988$.

[33] G. M. Cunningham, W. E. Mulham, P. L. Milthorpe, and J. H. Leigh, Plants of Western New South Wales, Inkata Press, Melbourne, Australia, 1992.

[34] J. D. Gibbons, Nonparametric Statistical Inference, Marcel Dekker, New York, NY, USA, 1985.

[35] M. K. Pasha and R. K. Das, "Quick viability test of soybean seeds by using tetrazolium chloride," Seed Science and Technology, vol. 10, no. 3, pp. 651-655, 1982.

[36] F. B. Salisbury and C. W. Ross, Plant Physiology, Wadsworth Publishing Company, Belmont, Calif, USA, 4th edition, 1992.

[37] G. R. Mari and J. Chengying, "Energy analysis of various tillage and fertilizer treatments on corn production," American-Eurasian Journal of Agricultural and Environmental Science, vol. 2, no. 5, pp. 486-497, 2007.

[38] Z. R. Helsel, "Energy and alternatives for fertilizer and pesticide use," in Energy in Farm Production, vol. 6, pp. 177-201, Elsevier, New York, NY, USA, 1992.

[39] K. J. Hülsbergen, B. Feil, S. Biermann, G. W. Rathke, W. D. Kalk, and W. Diepenbrock, "A method of energy balancing in crop production and its application in a long-term fertilizer trial," Agriculture, Ecosystems and Environment, vol. 86, no. 3, pp. 303-321, 2001.

[40] H. R. Langner, H. Böttger, and H. Schmidt, "A special vegetation index for the weed detection in sensor based precision agriculture," Environmental Monitoring and Assessment, vol. 117, no. 1, pp. 505-518, 2006. 


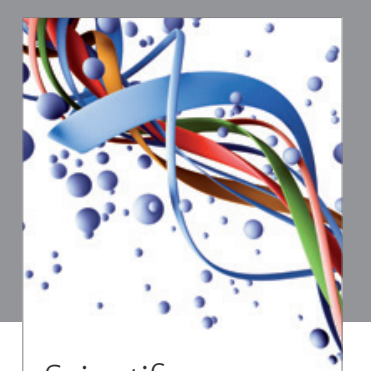

Scientifica
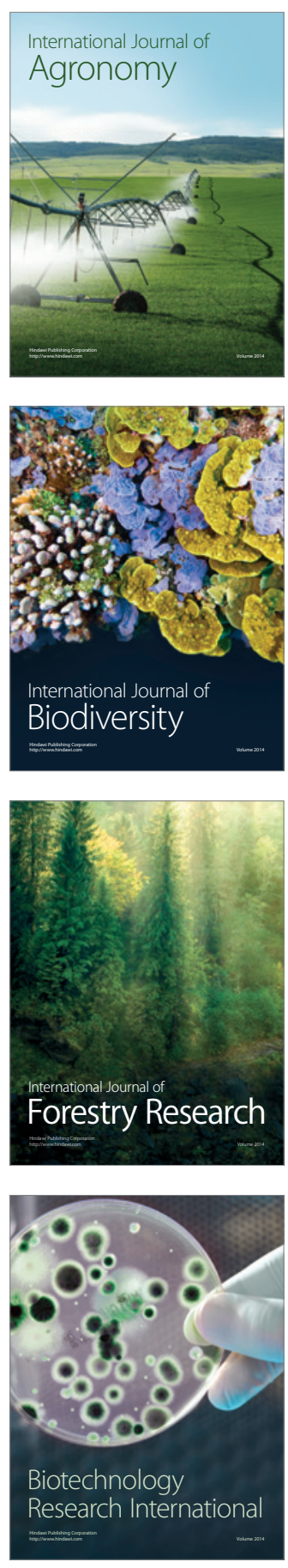
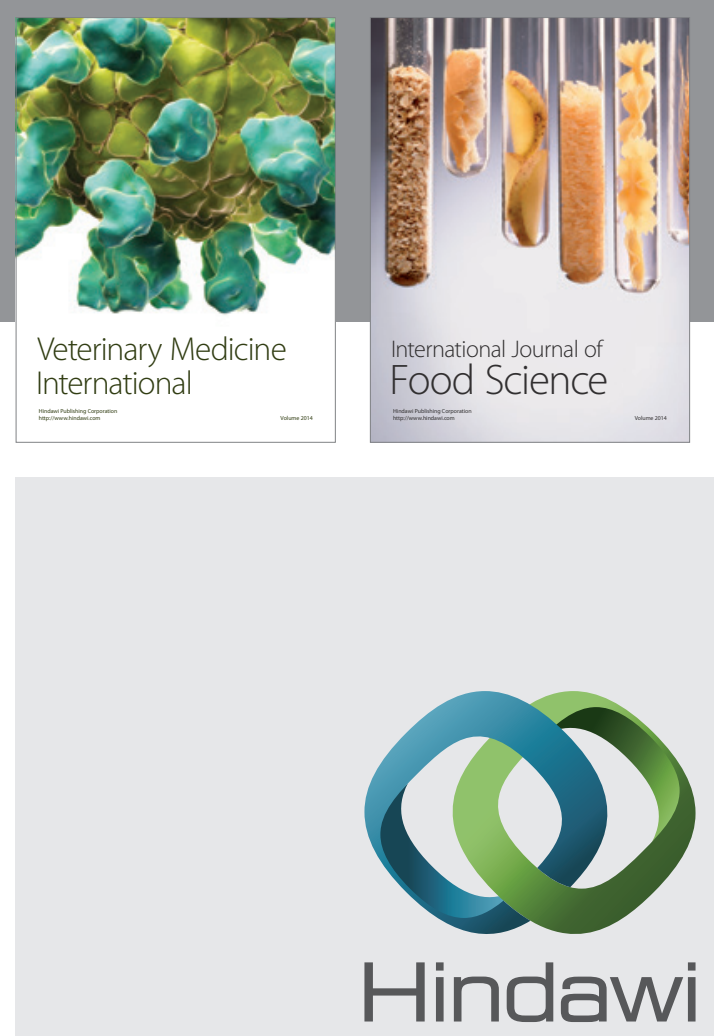

Submit your manuscripts at

http://www.hindawi.com
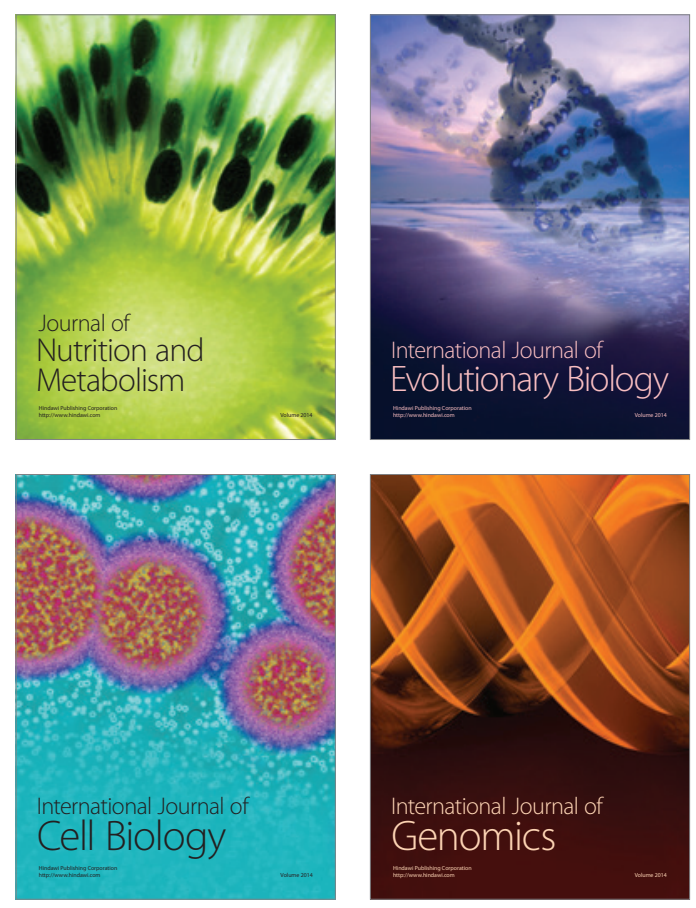
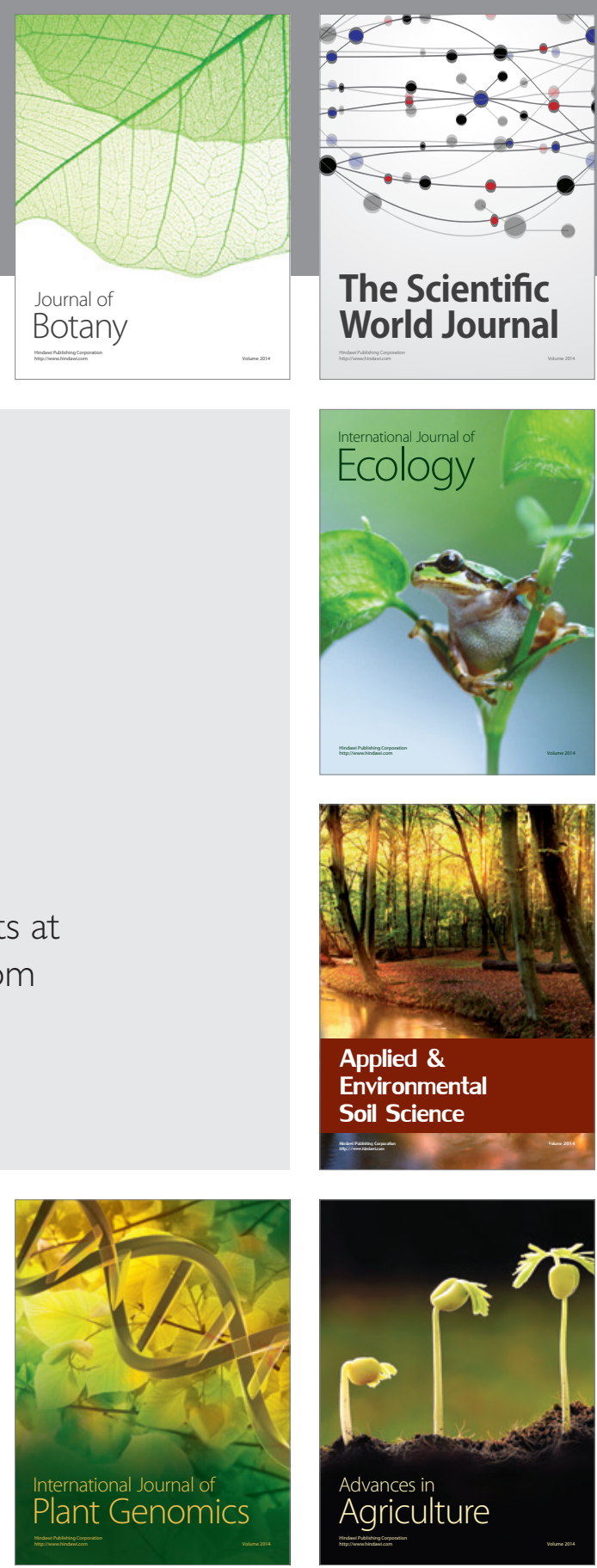

The Scientific World Journal
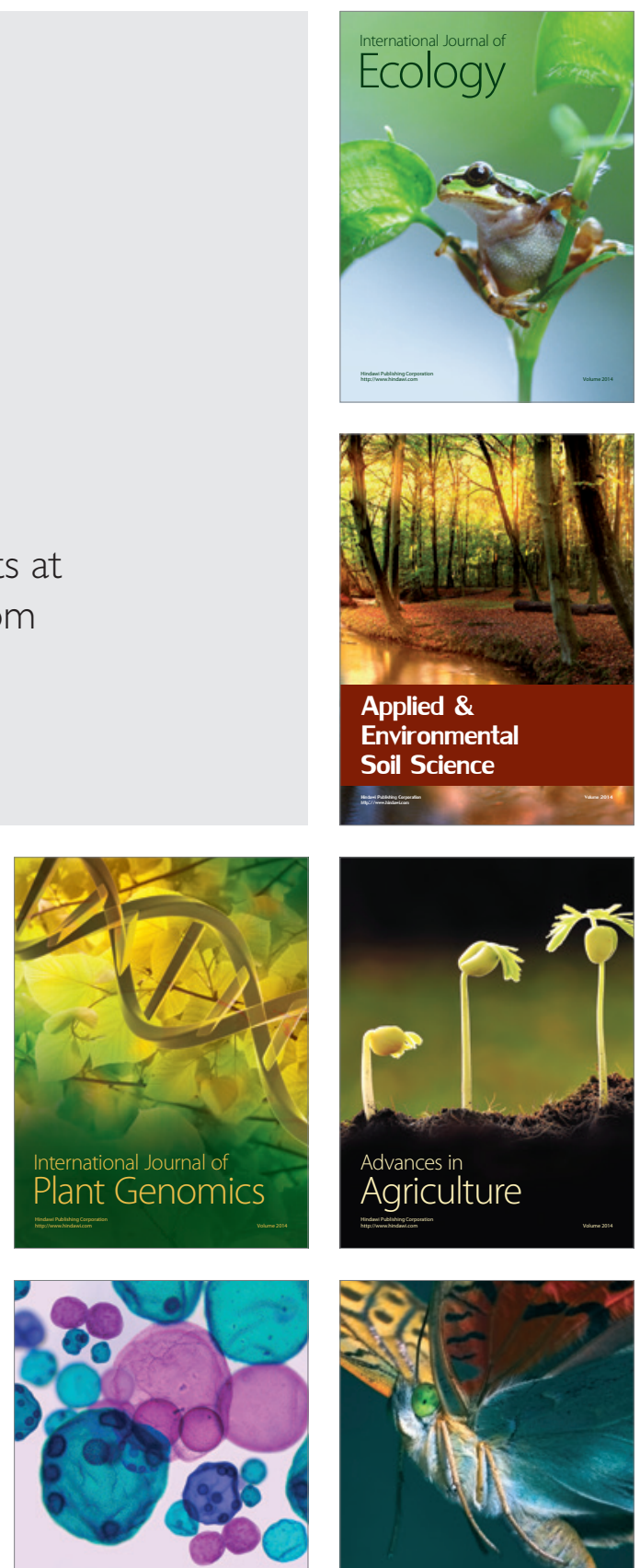

International Journal of Microbiology

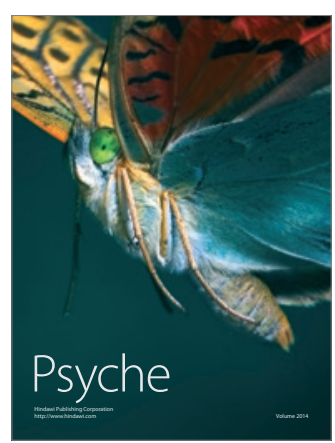

